\title{
Étienne Tabourot, Les Bigarrures du Seigneurs des Accords. Quatrième Livre avec Les Apophthegmes du Sr Gaulard
}

Michele Mastroianni

\section{(2) OpenEdition \\ Journals}

\section{Edizione digitale}

URL: http://journals.openedition.org/studifrancesi/34547

DOI: $10.4000 /$ studifrancesi.34547

ISSN: 2421-5856

\section{Editore}

Rosenberg \& Sellier

\section{Edizione cartacea}

Data di pubblicazione: 1 novembre 2005

Paginazione: 405

ISSN: 0039-2944

\section{Notizia bibliografica digitale}

Michele Mastroianni, «Étienne Tabourot, Les Bigarrures du Seigneurs des Accords. Quatrième Livre avec Les Apophthegmes du Sr Gaulard», Studi Francesi [Online], 146 (XLIX | II) | 2005, online dal 30 novembre 2015, consultato il 18 avril 2021. URL: http://journals.openedition.org/studifrancesi/34547 ; DOI: https://doi.org/10.4000/studifrancesi.34547

Questo documento è stato generato automaticamente il 18 avril 2021.

\section{cc) $($ ) $\ominus$}

Studi Francesi è distribuita con Licenza Creative Commons Attribuzione - Non commerciale - Non opere derivate 4.0 Internazionale. 


\title{
Étienne Tabourot, Les Bigarrures du Seigneurs des Accords. Quatrième Livre avec Les Apophthegmes du Sr Gaulard
}

\author{
Michele Mastroianni
}

\section{NOTIZIA}

ÉTIENNE TABOUROT, Les Bigarrures du Seigneurs des Accords. Quatrième Livre avec Les Apophthegmes du Sr Gaulard, édition collective par le Groupe Renaissance \& Âge classique (GRAC) de l'Université Lyon II, coordonnée par G.-A. PÉROUSE, Paris, Champion («Textes de la Renaissance», 84), 2004, pp. 293.

1 A quasi vent'anni di distanza dall'edizione del Premier Livre delle Bigarrures (ed. F. Goyet, Genève, Droz, 1986: cfr. questi «Studi», 91, 1987, p. 109) esce a cura del GRAC di Lione la seconda parte dell'opera in un'edizione collettiva a cura di G.-A. Pérouse, coadiuvato da M. Clément, R. Dubuis, Th. Mantovani e M. Paquant. Si tratta del Quatrième Livre (in realtà il secondo e il terzo non furono mai scritti, perché, come afferma Tabourot difendendo le sue fantasie, «ce volume entier ne seroit pas bien bigarré, s'il suivoit la façon des ordinaires escrivains»). Abbiamo così criticamente edito il corpus completo delle Bigarrures, testo indubbiamente singolare e interessante sul piano documentario, storico e linguistico. Il Quatrieme Livre è fatto seguire da quegli Apophthegmes $d u \mathrm{Sr}$ Gaulard che già nell'edizione del 1585 accompagnavano le Bigarrures IV. Questi Apophthegmes, però, sono qui editi nella silloge ampliata di una seconda parte (da centoventisei pezzi si passa a duecentotrentasette) pubblicata nel 1599, nove anni dopo la morte dell'autore. G.-A. Pérouse ripercorre le traversie della composizione e ipotizza in modo assolutamente convincente che tutta la raccolta è opera di Tabourot. Non solo, gli editori sono anche convinti che Bigarrures IV, con la loro successione di discorsi seri (sull'educazione dei bambini, sul problema giuridico della distinzione degli 'ordini' nella società, sull'evoluzione della versificazione francese nel corso del secolo, sull' 'imposture' dei 'faux sorciers') costituiscano un unicum con gli Apophthegmes, repertorio 
di facezie in cui il buon senso si allea alla sfida della logica. Saremmo, così, in presenza di un'opera estremamente moderna in cui Rabelais e Montaignes sembrano incontrarsi. Dal punto di vista della filologia la presente edizione è esemplare. M. Paquant ha approntato un glossario accuratissimo degli Apophthegmes, accompagnato da Fiches lexicales che rappresentano uno strumento utilissimo di ricerca per lo storico della lingua. 